\title{
Comparison of the effectiveness of feminist therapy with sex therapy Based CBT on sexual intimacy in Betrayed Women
}

\author{
Bafandegan, Vahid
}

Ph.d Student. Department clinical psychology, Neyshabur University, Iran.

Corresponding Author: Bafandegan, Vahid.Ph.d Student. Department clinical psychology, Neyshabur University, Iran.

Received date: January 29, 2021; Accepted date: February 27, 2021; Published date: March 02,2021

Citation: Bafandegan, Vahid. (2021) Comparison of the effectiveness of feminist therapy with sex therapy Based CBT on sexual intimacy in Betrayed Women. Clinical Research and Clinical Trials. 3(1); DOI: 10.31579/2693-4779/021

Copyright: Copyright (C) 2021, Bafandegan, Vahid. This is an open access article distributed under the Creative Commons Attribution License, which permits unrestricted use, distribution, and reproduction in any medium, provided the original work is properly cited.

\begin{abstract}
The Present Study Aims to Comparison of the effectiveness of feminist therapy (FT) with sex therapy on sexual intimacy in female. This Study Was Typed of Experimental Studies with pre- test and Post-Test with Control Group. The Study Consisted of All woman Referred to the Counselling Centres in university Neyshabur City. A Sample of 36 People Was Selected Then Randomly Assigned to Two Experimental Groups and One Control Groups. The people inventory sexual intimacy Botlani (SII) Was Used for Data Collection Then Based on 12 Meetings 90 Minutes for the Experiment Groups. The Pre-Test and Post-Test Scores Were Analysed Using a Manova Test in the SPSS 20 Software. According to the Results of Showed feminist Therapy More Effect Than Other Experimental Group and Control Group $(\mathrm{p} \leq 0.001)$ so sex Therapy More Effect Than Control Group in Variable ( $\mathrm{p} \leq 0.001)$. The conclusion is that the feminist therapy approach can be used to increase sexual intimacy in developing Muslim societies.
\end{abstract}

Keyword: feminist therapy; sex therapy; inventory sexual intimacy (sii); women

\section{Introduction}

Today we have less psychotherapy research in the field of women than men. In this sense, therapeutic approaches have followed a coherent and unified approach since the 1970s. The result was some disorders in women, such as premenstrual syndrome in women (Kaylali. J., Brown, S. L., Wanamaker, K. A., \& Greiner, L. E, 2014). According to Accord (2017), women's studies are summarized in three waves, and the third wave emphasizes cultural-therapeutic approaches. Feminist therapy (FT) is also highly dependent on culture. Feminist therapy does not offer a specific package protocol and Depending on the researcher's studies. In Iranian culture, girls have a passive role due to mandatory Islamic laws and they do not have the right to choose in marriage. Hence, we are in society with numerous betrayals by men, which is never mentioned anywhere due to the propaganda of the system. It has led to the continuation of women's passivity in other aspects of her life, such as employment. And in the end, it does not lead to the flourishing of female talents. But striving for equality can lead to systematic growth of the whole family and consequently to the growth and perfection of the family (Farnam, F., Janghorbani, M., Raisi, F., \& Merghati-Khoei, E, 2014). Psychology texts consider marriage to be feminine and it is effective not only in promoting interpersonal communication but also in women's physiology, such as regulating the menstrual cycle. (Lorenz, T. K., Demas, G. E., \& Heiman, J. R, 2015). For this reason, a lot of research has been done in the field of couples. Bagarozzi (2014) considers intimacy as a basic need that is rooted in attachment. According to Bagarozzi, Batlani in Iran has done a similar research on Iranian culture and made an inventory. To understand the subject, research on couples is considered the best opportunity and many other researchers, such as Eric Erickson, Sullivan, and Balbi,

Have done research .Although they have been criticized a lot because women are ignored. For example, Eric Erickson has named his book 'The Eight Stages of Man' (Dadstan, P. 2001). Many approaches have addressed the issue of intimacy, such as therapeutic approaches: cognitive therapy, gestal therapy, sex therapy, etc. Intimacy is made up of many factors. These factors require a holistic approach that combines cognitive-behavioural approaches with existentialism \& .... Feminist therapy creates these conditions. This approach is considered as an integrated approach that builds all other approaches on the basis of power (Harrow, 1997). In other approaches to psychotherapy, such as the reality therapy approach, power is considered a need or the view of Islamic psychology in Iran considers power in the hands of men and Islamic psychology considers women as the property of men (It is important in Iran

- Especially in Muslim societies- which can be mentioned due to the prohibitions related to jurisprudence in research processes). In the feminist therapeutic approach, power is derived from the principles of modern sociology. Marx considers power to be based on tools and wealth and Foucault (1972) considers power in knowledge. Therefore, one of the factor of feminist therapy are the job and knowledge. Power in feminist therapy is analysed on the basis of "external and internal, situational and semantic. In the field of external awareness we have: 1.Inequality of power in the Islamic structural system that leads to the formation of defence mechanisms in women's interpersonal relationships 2.personal history such as the identification of sexual experiences (B.O.S.) 
3.betrayal, which is likened to acid droplets as a metaphor. In fact, the necessary tools such as VIS, "B.O.S", GOF (emotional fog) or "Social, historical and Interpersonal" narratives are important for the client's formulation (Brown, L. S, 1986). In our research, we emphasize the Criticism and Rejection of Islamic rules rather than the solid principles of theory. Like Criticism and Rejection the story of Eve in the Qur'an, or the role of the media, which emphasizes Feminine passivity like the movie Davat. In Shia Aslam, sex is reserved for men, a man can marry up to four women at a time, while in women, and even sexual expression is shameful. According to the above topics, the therapist plays a sensitizing and informative role responsibly with client-centred approach (Accord, 2017). Classical feminists such as Helen Deutsch and Horne began their research mainly in the field of sex, which was rooted in Freud's theory. Freud saw healing in solving sexual oppression. In fact, he considered sexual issues as his independent variable. Sex is a biological perspective, it plays a significant role in the formation of a person's ego as the structure of his personality. Reports show a 30\% role in the variance of marital conflict. (Jafarbiglo .E. A ; Bakeries. S

;dadkhahtehrani .T, 2017). Sex therapy teaches the physiology and stages of the sex cycle

Based on the theories of Masters Johnson and Keynes (Kaplan 2013). Of course, each stage covers a wide range of psychological matters. Like ritual in the first stage. It also addresses the issue of intimacy. In the next stage is based on the first stage and intimacy is effective in it (korrow, R, 2013). In marriage, a woman benefits more than a man (Brizendine, $L$, 2006). It is different in Shia. The main reason is the approval of Islamic jurisprudence. And sometimes rape is seen among them. For example, the illegitimate relations of Salman Khodadai (Member of Parliament), a close associate of Khamnei, and the killing of the female victim. On the other hand, taboos in Iran are more feminine than male....

\section{Methodology}

The Present Study Is the Type of Semi Experiment Studies, Pre Test Post Test with Control Group: 2 experimental group and 1 control group. The Study Consisted of All student (female) Neyshabur City. 36 people based that 12 people Receive Feminist Therapy, 12 people sex Therapy and 12 people Were Control Group. First, the Announcement Was Made to Select the Sample 42 Have the Condition to Enter the Study. The People Have Problem Couse of Addiction, Mental Illness, Homicide, and Marital Infidelity Had Been Driven Out of the Study 36 people Selected Random They Have Been relationship at least Three Years; Their Age. In the Range of 20 to 50 Years. Selected 24 Couple Random Then based on 12 Meetings 90 minutes for sex therapy and 12 Meeting feminist therapy. The Control Group Did Not Receive Any Treatment, and They Were Told That They Are Waiting List in the Process of Treatment After Three Months. The Therapeutic Protocols Used in This Study Include a Package sex Method Therapy and Feminist Therapy

\section{Instrument}

\begin{tabular}{|c|c|c|c|}
\hline SD & $M$ & Stepp & Group \\
\hline 10.28 & 24.00 & Per Test & \multirow[t]{2}{*}{ Control } \\
\hline 9.87 & 44.25 & Post Test & \\
\hline 9.12 & 43.50 & Per Test & \multirow[t]{2}{*}{ Sex Therapie } \\
\hline 17.41 & 74.25 & Post Test & \\
\hline 8.95 & 42.92 & Per Test & \multirow[t]{2}{*}{ Feminist Therapie } \\
\hline 15.74 & 84.00 & Post Test & \\
\hline
\end{tabular}

Inventory sexual intimacy (SII), SII included 30 items each with a 4 choice range (always, sometimes, seldom, never) with 1-4 scores. As such, "always" gets 1 score and "never" gets 4 scores. Maximum and minimum scores are 120 and 40, respectively. Higher score in- dictates more sexual intimacy of the woman. The validity of content of questionnaire was confirmed, who were psychologists and consultants at Educational Sciences Department at Isfahan University and its reliability was investigated in a study conducted by Botlani and colleagues, on 140 People who had referred to Family Cultural Centre in Isfahan City in 2008 and Chronbach's alpha coefficient was obtained 0.81\% (Botlani S, Ahmadi A, Bahrami F, Shahsiah M, Mohebbi S, 2010)

Bohan (1992) states six guidelines for feminist practitioners to follow:

1. Therapists are knowledgeable concerning gender role socialization and the impact these standards have on what it means to be a woman or a man.

2. Therapists are aware of the impact of the distribution of power within the family and power differentials between men and women in terms of decision making, child rearing, career options, and division of labor.

3. Therapists understand the sexist context of the social system and its impacts on both the individual and the family.

4. Therapists are committed to promoting roles for both women and men that are not limited by cultural or gender stereotypes.

5. Therapists acquire intervention skills that assist clients in their gender role journey.

6. Therapists are committed to work toward the elimination of gender role bias as a source of pathology in all societal institutions.

Intervention Package Sex therapy, Bilal, A. (2020):Session1: Case formulation in the context of unique psychosexual history

Session2: Reconstruction of sexual attitudes, Socratic dialog

Session3: Exploration of automatic thoughts and catastrophization...

Session4: relaxation exercises and mindfulness, to help the client control negative stress

Session5: learning sexual communication and love skills (spending time together, emotional expression, love talk, surprise gifts)

Session6: Review of relaxation exercises and mindfulness Session7: Review of love and sexual communication skills Session8: Review of sensate focus

Session9: Homework Assignment: Stop and Start Technique with a lubricant Session 10: Review of stop and start technique

Session 11: Review of home assignments and discussion about hot issues Session12: ermination of therapy, review of therapy goals and outcomes

\section{Finding}

Before using the analysis of covariance test, the normality of the distribution, data scatter, homogeneity of error variance, and homogeneity of regression lines were checked. All three hypotheses were confirmed, That is, it is allowed to perform ANCOVA. As shown in Table One Mean sexual intimacy of sex therapy group and feminist therapy group increased in the post- test. But there was a very small difference in the pre-test and post-test of the control group. 
obtained with $\mathrm{DF}=36.3$ a significance level of $5 \%$ larger than $\mathrm{F}$ in the table. Therefore, the zero hypothesis is not confirmed. In other words, with 95\% confidence level, at least one of the treatment has an effect on
Women's sexual intimacy. Now we have to check: Which has a significant effect? Post hoc tests should be used (Bonferoni method)

\begin{tabular}{|c|c|c|c|c|c|}
\hline Sig & $\mathrm{F}$ & Sun of Square & Df & Sun of Square & Source \\
\hline 0.000 & 34.033 & $3723 / 361$ & 3 & 11170.082 & Corrected Model \\
\hline 0.008 & 7.989 & 874.000 & 1 & 874.000 & Intersepta \\
\hline 0.008 & 4.948 & 869.582 & 1 & 869.582 & Per Test \\
\hline \multirow[t]{4}{*}{0.000} & 48.681 & 5325.929 & 2 & 10651.858 & $\begin{array}{l}\text { Group(independent } \\
\text { variable) }\end{array}$ \\
\hline & & 109.404 & 32 & 3500.918 & Error \\
\hline & & & 36 & 178696.000 & Total \\
\hline & & & 35 & 14671.00 & Corrected Total \\
\hline
\end{tabular}

According to the findings presented in this table. There is a statistically significant difference between the mean of the control group with both experimental groups $(\mathrm{P}<0.01)$. The mean of the experimental groups is statistically higher than the mean of the control group. There is also a significant difference between the means of the experimental groups. The average sexual intimacy of the feminist therapy group is higher than the sex therapy group.

\begin{tabular}{|c|c|c|c|c|}
\hline Sig & SD & $\begin{array}{ll}\text { Average } & \text { of } \\
\text { difference } & \end{array}$ & Group b & Group a \\
\hline 0.001 & 4.272 & -30.386 & Sex therapy & \multirow[t]{2}{*}{ Control } \\
\hline 0.001 & 4.280 & -40.856 & Feminist therapy & \\
\hline 0.001 & 4.272 & 30.386 & Control & \multirow[t]{2}{*}{ Sex Therapie } \\
\hline 0.004 & 4.273 & -10.200 & Feminist therapy & \\
\hline
\end{tabular}

\section{Conclusion}

Hornei was of the opinion: Women, like men, have a genital tract but it is inside the body And Freud ignored it. If women have a masculine complex, men are womb envy. In the continuation of Horney's theories, Forward, S. (2010) addressed the role of a feminist in the couple. She has worked only on women and has achieved many successes. And he believes that the only way to save the relationship is The Self-Confidence Formula for Women in society. A summary of previous theories can be seen in Laura Brown's view (1986). Feminist therapy focuses on both industry and employment and it is an up-to-date approach. It emphasizes empowering target groups such as the disabled, the poor, and children. In the realm of couples, women's awareness and the right strategy for the symptoms in the family is important. Another dimension of feminist therapy is employment. The economy leads to independence. And women's independence means women's liberation from Islamic commandments and leads to the growth of later generations, especially girls in families (Papalia, D. E., Olds, S. W., \& Feldman, R. D, 2007). Hare-Mustin, R. T. (1984) with feminist psychotherapy has shown a significant increase in empowering variables compared to other approaches.

\section{References}

1. Accord (2017). Exist procedures for married woman.

2. Bagarozzi, D. A. (2014). Enhancing intimacy in marriage: A clinician's guide. Routledge

3. Bilal, A. (2020). Cognitive Behavioral Sex Therapy: An Emerging Treatment Option for Nonorganic Erectile Dysfunction in Young Men: A Feasibility Pilot Study. Sexual Medicine, 8(3), 396-407.

4. Bohan, J. S. (1992). Re-placing women in psychology: Readings toward a more inclusive history. Kendall/Hunt Publishing Company.

5. Botlani S, Ahmadi A, Bahrami F, Shahsiah M, Mohebbi S(2010) Effect of attachment-based couple therapy on sexual satisfaction and intimacy. J Fundam Ment Health; 12: 496-505.

6. Brizendine, L. (2006). The female brain. Broadway Books

7. Brown, L. S. (1986). From alienation to connection: Feminist therapy with post-traumatic stress disorder. Women \& Therapy, 5(1), 13-2

8. Dadstan, P. (2001). Morbid and developmental psychology from childhood to adulthood. Tehran: SAMT publication.

9. Farnam, F., Janghorbani, M., Raisi, F., \& Merghati-Khoei, E. (2014). Compare the effectiveness of PLISSIT and sexual health models on Women's sexual problems in Tehran, Iran: a randomized controlled trial. The journal of sexual medicine, 11(11)

10. Forward, S. (2010). Toxic in-laws: Loving strategies for protecting your marriage. Harper Collins

11. Foucalet .M (1972). Power - knowledge. Publisher: pantheon books. New York

12. Goodman, L. A., Liang, B., Helms, J. E., Latta, R. E., Sparks, E., \& Weintraub, S. R. (2004). Training counselling psychologists as social justice agents: Feminist and multicultural principles in action. The counselling psychologist, 32(6), 793-836.

13. Hare-Mustin, R. T. (1984). A feminist approach to family 
therapy. In The Gender Gap in Psychotherapie (pp. 301-318). Springer, Boston, MA.

14. Harrow, K. W. (1997). Women with open eyes, women of stone and hammers: Western feminism and African feminist filmmaking practice. Matatu, 19(1)

15. Jafarbiglo .E . A ; bakaie. S ;dadkhahtehrani .T (2017) Marital satisfaction in menopause woman with without sex dysfunctional. Journal of mid wifery and reproductive health.

16. Kaplan, H. S. (2013). New sex therapy: Active treatment of sexual dysfunctions. Routledge.

17. Kaylali. J., Brown, S. L., Wanamaker, K. A., \& Greiner, L. E.
(2014). A quantitative exploration of gendered pathways to crime in a sample of male and female juvenile offenders. Feminist Criminology, 9(2), 113-136.

18. Korrow, R. (2013). Sex research and sex therapy: A sociological analysis of Masters and Johnson (Vol. 32). Routledge

19. Lorenz, T. K., Demas, G. E., \& Heiman, J. R. (2015). Interaction of menstrual cycle phase and sexual activity predicts mucosal and systemic humoral immunity in healthy women. Physiology \& behavior, 152, 92-98

20. Papalia, D. E., Olds, S. W., \& Feldman, R. D. (2007). Human development. McGraw-Hil
This work is licensed under Creative Commons Attribution 4.0 License

\section{To Submit Your Article Click Here: Submit Manuscript}

DOI: $10.31579 / 2693-4779 / 021$

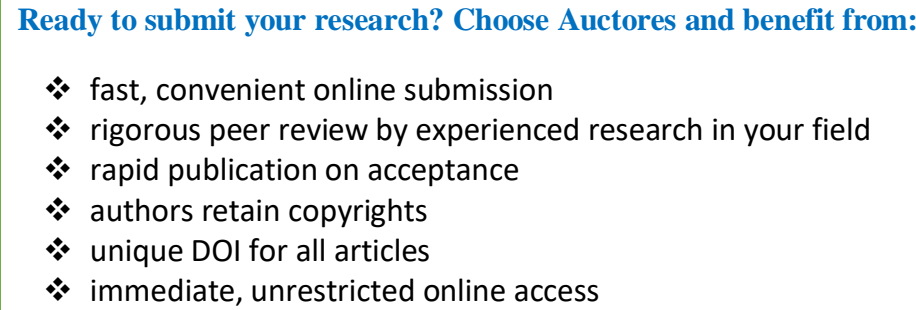

At Auctores, research is always in progress.

Learn more www.auctoresonline.org/journals/clinical-research-andclinical-trials 